\title{
A macrometropolização em São Paulo: reterritorialização, reescalonamento e a cidade-região*
}

\author{
Macro-metropolization in São Paulo: \\ reterritorialization, rescaling and the city-region
}

Pedro Henrique Campello Torres [I]

Ruth Ferreira Ramos [II]

Amauri Pollachi [III]

\section{Resumo}

A escala de planejamento regional está associada às transformações no âmbito econômico, no qual a globalização e os processos de reescalonamento são fundamentais para se compreender o desenvolvimento desigual. Este artigo discute aspectos conceituais e empíricos dos processos de metropolização do espaço, a partir do estudo da Macrometrópole Paulista (MMP), tendo como referência teórica os conceitos de reterritorialização e de reescalonamento. Para tanto, caracterizamos o território macrometropolitano com o objetivo de verificar se os conceitos de reterritorialização e reescalonamento propostos por Neil Brenner para o contexto da União Européia podem ser aplicados ao quadro brasileiro, sobretudo para o caso de São Paulo e da MMP. Concluímos que a MMP é uma instituição estatal emergente, reescalonada para reterritorialização do capital.

Palavras-chave: reterritorialização; reescalonamento; cidade-região; Macrometrópole Paulista; metropolização.

\begin{abstract}
The regional planning scale is associated with transformations in the economic sphere, in which globalization and rescaling processes are fundamental aspects to the understanding of uneven development. This article discusses conceptual and empirical aspects of space metropolization processes based on the study of the São Paulo Macrometropolis. The theoretical reference is constituted by the concepts of reterritorialization and rescaling. We characterize the macrometropolitan territory in order to verify whether these concepts, proposed by Neil Brenner for the context of the European Union, can be applied to the Brazilian framework, especially to the São Paulo Macrometropolis. We conclude that this macrometropolis is an emerging state institution, rescaled for reterritorialization of capital.
\end{abstract}

Keywords: reterritorialization; rescaling; city-region; São Paulo Macrometropolis; metropolization. 


\section{Introdução}

A temática da (re)configuração de novas regiões, escalas e territórios em um mundo globalizado e neoliberal tem recebido atenção da literatura especializada, interessada nos novos processos de produção do espaço capitalista (Brenner e Theodore, 2005). Inúmeros trabalhos no campo do planejamento territorial - e nas ciências correlatas - foram publicados tendo essa conjuntura como motriz para a compreensão desse processo contemporâneo (Storper, 1996; Sassen, 1991; Soja, 2000; Scott, 2001; Ribeiro, Santos Júnior e Azevedo, 2009, entre outros). Cidades globais, cidades-regiões, megarregiões, megacidades, megalópoles, territórios transfronteiriços são exemplos de novas abordagens e compreensão de fluxos e dinâmicas dessa nova realidade.

Na última década, o governo do estado de São Paulo propôs a delimitação da Macrometrópole Paulista (MMP) como nova escala de planejamento e governança (Zioni et al., 2019; Negreiro, Santos e Miranda, 2015; Emplasa, 2011a; Asquino, 2010), no bojo dos processos de regionalização e reorganização das regiões metropolitanas paulista. Ainda que não esteja formalmente institucionalizada por atos normativos do governo estadual, a região tem se configurado como unidade de planejamento territorial, inclusive com dotações orçamentárias previstas no Plano Plurianual de São Paulo (Tavares, 2018). Essa nova categoria regional vem sendo estudada de diferentes perspectivas analíticas, que se dedicam a compreender os processos e os efeitos da metropolização do espaço.

São exemplo desses estudos, os artigos de (1) Cunha et al. (2013), que versa sobre a mobilidade pendular na MMP; (2) de Tavares
(2016), que aborda o planejamento da MMP baseado em eixos de infraestrutura; (3) de Silva, Cunha e Ortega (2017), que trata da constituição da MMP a partir da dimensão demográfica; (4) de Pasternak e Bógus (2019) que apresenta a estrutura sócio-ocupacional da MMP; (5) de Torres, Ramos e Gonçalves (2019), que expõe a relação entre a expansão metropolitana e os conflitos socioambientais na MMP; e (6) de Jacobi, Cibim e Leão (2015) em relação à crise hídrica, entre outros trabalhos. Além da dissertação de Gomes (2018), estudo pioneiro em relação ao Plano de Ação da Macrometrópole e a priorização do Estado em relação ao setor de transporte e logística.

O foco do presente trabalho, por sua vez, está no entendimento da ação do governo estadual em forjar a cidade-região macrometropolitana, a partir das definições de reescalonamento e reterritorialização estruturadas por Brenner (2018). Como esse debate se aplica em um contexto de Sul Global? Mais do que isso, como esse processo está em curso em âmbito subnacional, como, por exemplo, no caso de São Paulo e a formação da Macrometrópole Paulista? Ela é uma região sem paralelos em termos de conformação da unidade físico-territorial, número-populacional, PIB, entre outros aspectos? Ela marca o reescalonamento e uma reterritorialidade de um ou mais territórios? Qual estratégia institucional do Estado em sua formação?

Com o objetivo de responder a tais perguntas, verificaremos se os conceitos de reterritorialização e reescalonamento propostos por Brenner (ibid.) para o contexto da União Européia podem ser aplicados ao quadro brasileiro, sobretudo para o caso de São Paulo e da MMP. O propósito aqui não é buscar uma aculturação epistemológica, mas iluminar 
diferenças e semelhanças que possam contribuir para a produção de uma interpretação alicerçada nas especificidades do Sul Global, no intuito de subsidiar o debate contemporâneo sobre os processos de metropolização no Brasil, suas dinâmicas, escalas e estratégias (Klink, 2013).

Em sua delimitação, essa região, ou a cidade-região (Lencioni, 2015a; Pasternak e Bógus, 2019), abriga as Regiões Metropolitanas de São Paulo, Campinas, Vale do Paraíba e Litoral Norte, Baixada Santista e Sorocaba; além das Aglomerações Urbanas de Jundiaí e de Piracicaba e a Unidade Regional Bragantina (não institucionalizada), totalizando 174 municípios (Figura 1). Concentra uma população de 33,6 milhões de habitantes, que corresponde a $74,6 \%$ do total da população do estado de São Paulo, segundo dados do Emplasa - Empresa Paulista de Planejamento Metropolitano, de 2018.

A escala de planejamento regional está associada às transformações no âmbito econômico, no qual a globalização e os processos de reescalonamento são fundamentais para se compreender o desenvolvimento desigual (Brenner, 2010; Klink, 2013; Souza, 2016, Brandão, Fernandez e Ribeiro, 2018). No discurso oficial do governo estadual, a escala macrometropolitana configura-se como oportunidade

Figura 1 - Regiões metropolitanas

e aglomerações urbanas da Macrometrópole Paulista

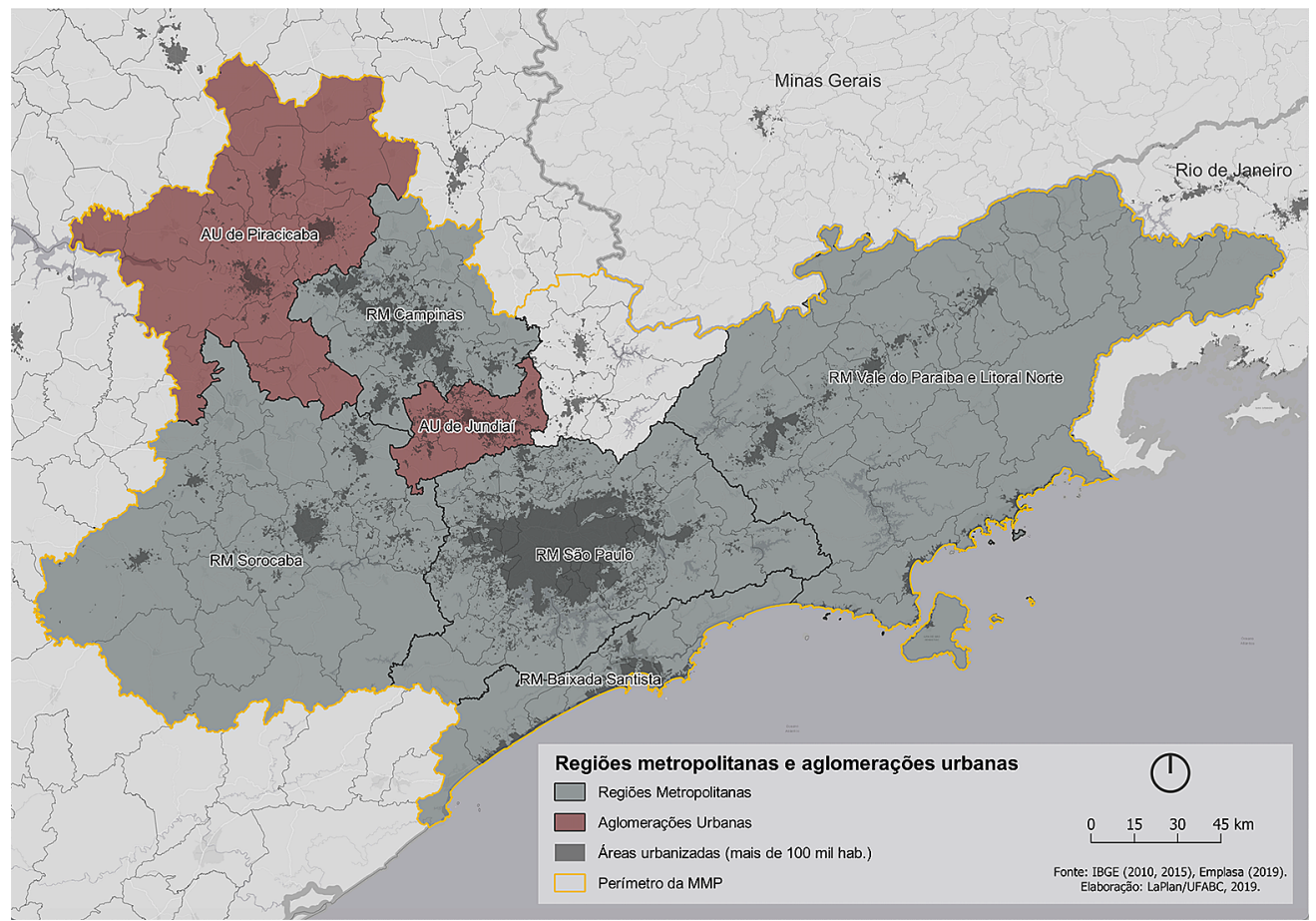

Fonte: IBGE (2010, 2015), Emplasa (2019). Elaboração LaPlan/UFABC, 2019. 
para promover o desenvolvimento integrado das regiões metropolitanas paulistas e a diminuição dos desequilíbrios regionais (Emplasa, 2014). Nossas conclusões preliminares, no entanto, indicam a manutenção das distorções entre as regiões, com alta concentração de investimentos na Região Metropolitana de São Paulo em detrimento das demais.

Reflete-se, ainda, a máxima de Lefebvre, recuperada por Brenner, de que "somente o Estado pode assumir a tarefa de administrar o espaço 'em grande escala'" (2018, p. 64). $\mathrm{Na} \mathrm{MMP}$, o neoliberalismo à brasileira (Oliveira, 1995) traz contornos singulares quanto ao papel do Estado como ator central e impulsionador de uma estratégia para forjar uma nova territorialidade. Em São Paulo, entre 1995 e 2018, o mesmo partido (Partido Social Democrata Brasileiro, PSDB) prioriza práticas neoliberais e assume "o administrar o espaço 'em grande escala'". Se as cidades, e seus conjuntos, são modelos de territorialização do capital, com aglomeração de infraestrutura fixa e imóveis, como sistemas de transporte, suprimento de energia e redes de comunicação, parece-nos que a Macrometrópole Paulista pode ser definida como o modelo último de realização desse processo, com o objetivo de proporcionar uma estrutura geográfica estável para circulação do capital em múltiplas escalas, assim como de força de trabalho, logística e de mercadorias.

Após essa breve contextualização inicial, na próxima seção apresentamos a metodologia utilizada. Em seguida, abordamos a questão da cidade-região e examinamos o papel protagonista do governo estadual na proposição da escala macroregional. Concluindo, discutimos a emergência da MMP, estabelecendo relações com os conceitos de reterritorialização e reescalonamento (Brenner, 2018) para a conjuntura em questão.

\section{Metodologia}

O capítulo "A globalização como reterritorialização: o reescalonamento da governança urbana na União Europeia" (ibid.) apresenta as categorias de reterritorialização e de reescalonamento da governança urbana que serão aqui testadas para o contexto da Macrometrópole Paulista. Entende-se, por reterritorialização, a reconfiguração, e o reescalonamento de formas de organização territorial, como cidades e Estados.

Para Brenner (ibid.) "novas macrogeografias de acumulação de capital" têm se consolidado no âmbito de uma ordem econômica mundial em escalas supranacionais, em que o exemplo mais claro é a União Européia, mas também blocos na América do Norte e Ásia Oriental. Para o autor, nas escalas espaciais subnacionais, como a Macrometrópole Paulista, a competição interespacial entre as regiões urbanas estaria se intensificando para atrair investimentos, sendo primordial o papel do Estado em estabelecer vantagens locacionais e ofertar subsídios. As perguntas que servem de fio condutor à análise aqui oferecida são (1) se os quadros analíticos e exemplo propostos por Brenner podem ser aplicados considerando a especificidade brasileira e (2) quais os possíveis limites dessa contribuição conceitual.

Para respondê-las, inicialmente realizamos leitura crítica do Plano de Ação da Macrometrópole Paulista 2013-2040 (PAM), com o objetivo de entender o papel e a visão 
do Estado para a região e as características de cada vetor de desenvolvimento proposto, sobretudo no que tange ao desequilíbrio regional entre regiões metropolitanas e aglomerações urbanas que compõem a MPP e são tão distintas socioeconomicamente.

Complementando essa etapa, realizamos pesquisa na plataforma da Imprensa Oficial do Governo de São Paulo, tendo como descritor o termo "Macrometrópole Paulista", resultando em 467 documentos entre 17 de agosto de 2006 (primeira ocorrência do termo) e 30 de maio de 2019. 0 objetivo de verificar o descritor "Macrometrópole Paulista" na publicidade legal do Estado (Diários Oficiais do Executivo ou Legislativo) foi buscar o entendimento de como a região, embora não institucionalizada por atos normativos do executivo, configura-se como referência nas políticas públicas no âmbito estadual e como, ou para quais áreas, projetos e estratégias isso tem ocorrido.

\section{A promoção da cidade-região paulista}

Partindo do pressuposto lefebvriano de que "toda escala espacial é uma estrutura geográfica socialmente produzida desterritorializando e reterritorializando no processo capitalista" (Brenner, 2018, p. 70), torna-se imperativo compreender as estratégias do Estado na produção do espaço macrometropolitano paulista. 0 mesmo argumento é compartiIhado por Chelotti (2010, p. 167) em diálogo com Haesbaert (2006), para quem "todo processo de desterritorialização é procedido de uma reterritorialização, seja na dimensão econômica, política, ou cultural" .
Em âmbito global, as crises econômicas do capitalismo, como no pós-1979, configuraram-se como momentos de descentralização da escala nacional de acumulação, urbanização e regulamentação estatal em favor de novas configurações territoriais e sub e supranacionais (Brenner, 2018, p. 70). 0 mesmo movimento pode ser observado no Brasil, para o qual, de acordo com Klink, Oliveira e Zimerman
Likewise, the post-1990 scenario of a more open trade regime, globalization, deregulation, and increased competition, coupled with the restructur-ing of the Brazilian national developmental state, has undermined the leverage of the national scale in the production of urban and regional spaces. (2013, p. 35)

Nesse quadro, nota-se que a formação da Macrometrópole Paulista coincidiu com o pós-crise econômica de 2008 e a retomada, pelo governo federal, de robustos investimentos na economia, com destaque para o setores de habitação, saneamento, energia, transporte e logística. Mas qual o papel, ou estratégia, do governo de São Paulo nesse processo? Contrapor de alguma maneira o investimento e o protagonismo do governo federal nessa arena de reconfiguração da circulação do capital ou, ao contrário, garantir a maior circulação possível de capital, mercadorias e força de trabalho nesse território? Qual o papel das cidades e dos estados territoriais como estruturas geográficas dentro, sobre e por meio das quais o desenvolvimento capitalista se desenrola? É o que destaca Brenner (2018, p. 66):

Cidades e estados estão sendo reconfigurados, reterritorializados e reescalonados em conjunto com o mais recente 
ciclo de globalização capitalista, mas ambos permanecem sendo formas essenciais de organização territorial sobre as quais se baseia a circulação de capital em escala mundial.

A Macrometrópole Paulista tem São Paulo por centro irradiador que, segundo o IBGE (2008) apud Moura e Pêgo (2017) possui “[...] projeção e vínculos sobre todas as Unidades da Federação (UF) e centros até o nível de capital regional Brasil". Portanto, é parte do subsistema urbano Sudeste que se distingue:

pela presença dos principais centros de gestão pública e empresarial, sob apoio de uma economia pautada na atividade industrial diversificada, comércio e serviços que se sobressaem pela especialidade, variedade, qualidade e sofisticação, atividades financeiras, tecnológicas, informações e comunicações. Uma multiplicidade multidirecional de fluxos materiais e imateriais perpassa esse território e o conecta nacional e internacionalmente, posicionando-o em condições de comparabilidade superior aos demais subsistemas. (p. 75)

Neste sentido, estudos mais recentes sobre os atuais processos de produção e organização do espaço metropolitano têm auxiliado na compreensão da Macrometrópole Paulista como fenômeno metropolitano. Para Pasternak e Bógus (2019, p. 433), a MMP configura-se como um "complexo de metrópoles ao redor da Grande São Paulo". Na visão das autoras, não se trata da formação de um espaço homogêneo moldado em uma supermetrópole, mas de uma extensa área urbana estruturada devido à conurbação dos centros metropolitanos em torno da Região Metropolitana de São Paulo, em um complexo sistema de cidades. Diante de tais características, a escala macrometropolitana pode ser elucidada pelo conceito de cidade-região.

Lencioni (2011) e Campolina Diniz e Campolina (2007) já alertavam para a conformação de uma cidade-região a partir da expansão da Região Metropolitana de São Paulo. Para Lencioni "A metropolização do espaço é expressão de uma nova época, e muitos dos arcabouços teóricos que utilizávamos para compreender a metrópole e a região metropolitana se esgotaram (Lencioni, 2011, p. 146). Campolina alerta para o fato de que essa cidade-região "tenderá a reforçar a concentração regional no Brasil, coerentemente com as tendências mundiais de globalização e reforço das localidades mais desenvolvidas, como indicam os estudos sobre a formação das cidades-região globais à escala mundial (Campolina Diniz e Campolina, 2007, p. 41).

Frey (2019) propõe três dimensões fundamentais para auxiliar na compreensão do termo cidade-região: (1) espacial (2) econômica e (3) política-institucional. Na (1) dimensão espacial, a emergência do conceito de cidade-região está associada aos processos observados inicialmente na Europa e na América do Norte de expansão de uma cidade dominante para o entorno, com o surgimento de polos de importância econômica, em uma estrutura policêntrica. No entanto, outras configurações dessa expansão têm sido notadas, demonstrando que o fenômeno é "complexo e multifacetado" (ibid., p. 1), o que dificulta na construção do próprio conceito.

$\mathrm{Na}$ (2) perspectiva econômica, as cidades-regiões são vistas como "forças motrizes da economia mundial" (ibid.), sendo relevante compreendê-las a partir de sua capacidade de inserção e conexão em rede de cidades 
mundiais interconectadas, no contexto da globalização e de reterritorialização. Finalmente, as cidades-regiões também podem ser compreendidas a partir (iii) do papel do Estado na implementação e priorização de políticas de desenvolvimento regional. Se antes a ação estatal focava na distribuição dos recursos no território nacional, na atualidade as cidades-regiões constituem-se espaços prioritários para o desenvolvimento que visa à inserção no mercado global.

Ao relacionar esses dois estudos de Pasternak e Bógus (2019) e de Frey (2019), queremos reforçar que para uma melhor compreensão da MMP como cidade-região, além das dimensões espacial e econômica já destacadas pelos autores, é fundamental observar o papel do governo estadual ao estipular uma nova escala para as políticas de desenvolvimento regional (Brenner, 2018). Trata-se de movimento que acompanha, no âmbito subnacional, a continuidade de um desenvolvimento espacial neoliberalizado (Klink, 2013) no Brasil.

É importante ainda destacar que, na dimensão político-institucional, Frey (2019, p. 2) entende que é oportuno e necessário que os pesquisadores reflitam sobre o potencial das cidades-regiões de serem espaços para a inovação de práticas de governança que buscam "democracia, equidade e diversidade". Por isso, evidenciaremos como a categoria "macrometrópole paulista" passou a figurar nos instrumentos das políticas públicas de desenvolvimento regional do governo estadual, como relevante escala para o planejamento e a governança, complementando os resultados já revelados pelas pesquisas de Júnior e Castro (2017) e Tavares (2018).

Embora comumente a literatura afirme que "o termo Macrometrópole Paulista foi adotado pela Empresa Paulista de Planejamento Metropolitano, que então passa a utilizar tal designação nos planos oficialmente lançados a partir da instituição do Sistema Estadual de Desenvolvimento Metropolitano, em 2011" (Júnior e Castro, 2017, p. 712), nota-se que o governo estadual também empregava o termo "Macrometrópole de São Paulo" para planejamento dos recursos hídricos.

Assim, por meio de um decreto de 2008, foi criado um grupo de trabalho formado pelas secretarias de Economia e Planejamento, Saneamento e Energia e do Meio Ambiente visando a "propor alternativas de aproveitamento dos recursos hídricos da Macrometrópole de São Paulo". ${ }^{1}$ Ainda que relacionada especificamente ao planejamento dos recursos hídricos devido ao risco de exaustão dos mananciais, diante das projeções de incremento da demanda (Daee, 2013), a escala macrometropolitana como território prioritário para o planejamento hídrico foi adotada pelo Estado, como pode ser observado no conteúdo do ato normativo:

Artigo 20 - Para efeito deste decreto, a Macrometrópole de São Paulo é composta pelas Regiões Metropolitanas de São Paulo (RMSP), Campinas (RMC) e Baixada Santista (RMBS), acrescida de regiões limítrofes ou adjacentes de interesse para o objetivo dos trabalhos definidos no "caput" deste artigo. (São Paulo, 2008)

A criação de um grupo de trabalho específico composto por três secretarias diferentes, com o objetivo de elaborar estudos técnicos sobre a situação dos recursos hídricos da MMP, decorreu, sobretudo, por conta das obrigações estabelecidas pelo Departamento de Águas e Energia - Daee, em 2004, diante da 
renovação da outorga de uso de água do Sistema Cantareira para a Sabesp - Companhia de Saneamento Básico do Estado de São Paulo (Emplasa, 2014). Como resultado do grupo de trabalho dos atores estatais, em 2013 foi publicado o Plano Diretor de Aproveitamento de Recursos Hídricos para a Macrometrópole Paulista (Daee, 2013).

No âmbito da Emplasa, ${ }^{2}$ é com a publicação em 2010 do "Estudo da Morfologia e da Hierarquia Funcional da Rede Urbana Paulista e da Regionalização do Estado de São PauIo" que a Macrometrópole foi oficialmente delineada (Tavares, 2018; Emplasa, 2011a), tornando público que as delimitações de MMP propostas para o planejamento hídrico pelo Decreto estadual n. 52.742/2008 e para a questão regional pela Emplasa eram distintas. ${ }^{3}$

No ano seguinte, em 2011, a Emplasa publicou novo documento intitulado "Rede Urbana e Regionalização do Estado de São Paulo", retificando a demarcação do território macrometropolitano "para fins de planejamento e gestão de políticas públicas de desenvolvimento regional (Emplasa, 2011, p. 12). Mais recentemente, em 2014, foi publicado o Plano de Ação da Macrometrópole Paulista, onde a escala macrometropolitana, devido à sua importância socioeconômica, é assumida como prioritária para integração de políticas públicas. Nestes documentos oficiais produzidos pela Emplasa, é patente que a questão da infraestrutura, da competitividade econômica e da conectividade apresentam-se como prioridades políticas para o desenvolvimento regional (Tavares, 2016).

Para Tavares, a consolidação da MMP ocorreu entre os anos de 2008 e 2015 "com precisão de seus limites físico-administrativos e com uma estrutura institucional que lhe garantiu continuidade de ações" (Tavares, 2018, p. 125). Neste mesmo artigo, Tavares demonstra que desde os anos 1980, a pesquisa científica ao buscar a compreensão da urbanização dispersa e da reestruturação produtiva no estado de São Paulo, para além de influenciar na construção da Macrometrópole Paulista como objeto teórico-conceitual, também motivou o planejamento regional do governo do estado. ${ }^{4}$

Não é objetivo específico deste artigo apresentar uma trajetória histórica detalhada do uso do termo e da delimitação da MMP. ${ }^{5}$ Antes nos preocupamos em evidenciar a presença do termo "Macrometrópole paulista" na agenda de políticas públicas do governo estadual, sobretudo nas políticas de desenvolvimento regional. Embora seja notório que a agenda contemporânea da ciência de planejamento urbano e regional exerça influência na prática do planejamento (ibid.), também entendemos que é relevante evidenciar que, no processo de elaboração de políticas públicas urbanas, há interesses que são específicos de cada agenda política. Assim, se o uso do termo MMP e sua delimitação refletem uma nova maneira de abordar e entender os processos de metropolização ou mesmo uma mudança de paradigma na forma de planejar (Tavares, 2016), também revelam os temas prioritários da agenda política e as alternativas políticas consideradas.

O estado de São Paulo tem mantido o protagonismo na definição e delimitação dos espaços regionais, desde antes da Constituição Federal de 1988, que atribuiu aos estados federativos a responsabilidade de delimitar regiões metropolitanas. Ao estabelecer a MMP como nova escala de planejamento, trazendo as questões de infraestrutura, de transporte e 
de abastecimento de água como basilares para a competitividade econômica e conectividade, assume-se, também, uma opção política de planejamento regional.

Embora exista dificuldade de se delimitar exatamente o processo de invenção da Macrometrópole Paulista, de acordo com Tavares (2018) com a publicação do Plano de Ação da Macrometrópole 2013-2040 (PAM), a Macrometrópole Paulista inseriu-se no sistema de planejamento regional do estado de São Paulo e se constituiu como uma região institucionalizada (porém não regulamentada por lei específica). Indícios desse processo de estabelecimento de uma nova escala de planejamento podem ser evidenciados pela inclusão da MMP aos instrumentos de planejamento e políticas públicas do estado de São Paulo: o Plano Plurianual (PPA), a Lei de Diretrizes Orçamentárias (LDO) e a Lei Orçamentária Anual (LOA) ${ }^{6}$ passaram a definir orçamento específico para a MMP.
Composto por 4 volumes - (1) Política de desenvolvimento da MMP; (2) Uma visão da MMP; (3) Cenários e desafios da MMP; e (4) Carteira de Projetos PAM -, constata-se que o PAM optou por priorizar eixos ou vetores de desenvolvimento. ${ }^{7}$ Ainda que, na narrativa da visão do estado, a diminuição dos desequilíbrios regionais é tida como central, no mesmo documento, no volume Carteira de Projetos, o que se vê é o reforço dos atuais padrões de ocupação territorial e priorização de investimentos para o setor de infraestrutura e logística.

Na Tabela 1 e no Gráfico 1, desagregamos os projetos tidos como prioritários pelo governo do estado para MMP, separando-os pelos eixos propostos pelo Governo do Estado. O que fica evidente é a manutenção das desigualdades de investimentos e de prioridades por região, bem como o fato de a Região Metropolitana de São Paulo se estabelecer como eixo irradiador dessa região para atração e circulação de capital nesse território.

Tabela 1 - Quantidade de projetos e estimativa de investimento (em milhões de reais) por vetor territorial da Macrometrópole Paulista - 2025-2040

\begin{tabular}{|c|c|c|c|c|c|}
\hline \multirow{2}{*}{ Vetor } & \multirow{2}{*}{$\begin{array}{c}\text { Quantidade } \\
\text { projetos }\end{array}$} & \multicolumn{4}{|c|}{ Período } \\
\hline & & 2025 & 2035 & 2040 & Total \\
\hline Vetor Desenvolvimento RMSP & 13 projetos & $68.930,00$ & $97.340,00$ & $3.800,00$ & $170.070,00$ \\
\hline Vetor Desenvolvimento Bandeirantes & 10 projetos & $14.001,30$ & $10.016,70$ & - & $24.018,00$ \\
\hline Vetor Desenvolvimento Vale do Paraíba & 13 projetos & $7.419,30$ & $9.416,70$ & 250,00 & $17.086,00$ \\
\hline Vetor Desenvolvimento Caminho do Mar & 11 projetos & $3.188,00$ & $13.016,70$ & - & $16.204,70$ \\
\hline Vetor Desenvolvimento Sorocaba & 9 projetos & $8.115,30$ & $7.556,70$ & - & $15.672,00$ \\
\hline Vetor Desenvolvimento Perimetral da MMP & 10 projetos & $7.228,00$ & $3.727,00$ & - & $10.955,00$ \\
\hline Total & & $108.881,90$ & $141.073,80$ & $4.050,00$ & $254.005,70$ \\
\hline
\end{tabular}




\section{Gráfico 1 - Estimativa de investimento por vetor de desenvolvimento} 2025-2040

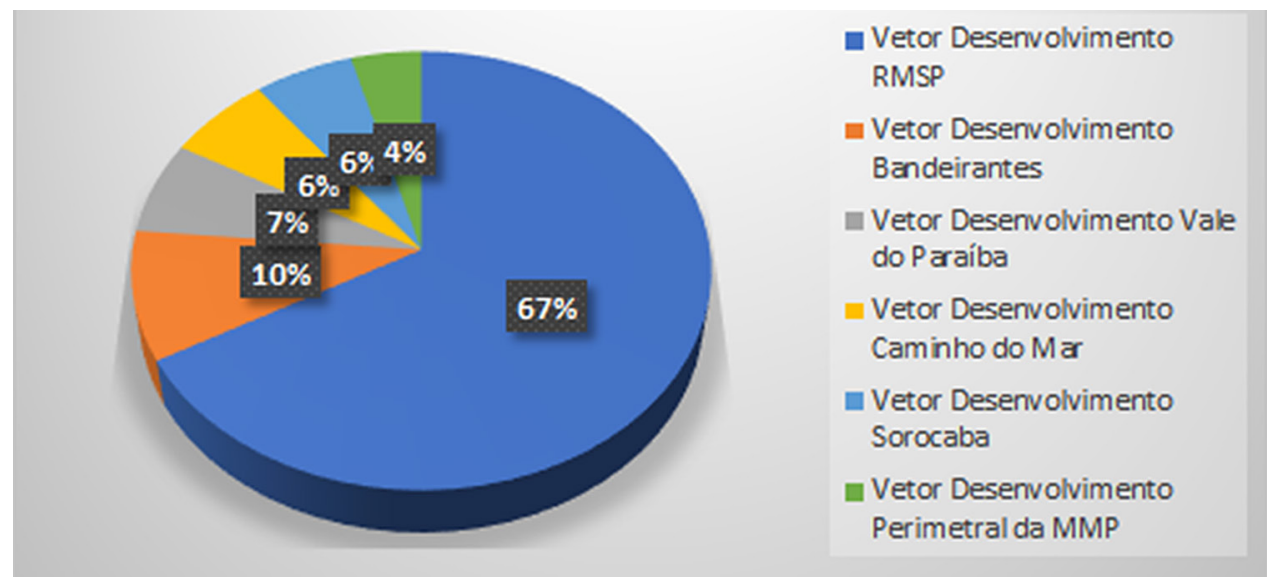

Fonte: Carteira de Projetos do PAM, Emplasa (2014). Organizado pelos autores.

\section{Quadro 1 - Projetos previstos para o Vetor Região Metropolitana de São Paulo}

\section{Vetor Região Metropolitana de São Paulo - 13 projetos}

I. Articulação do sistema de trens regionais com a rede de estações metroferroviário da RMSP

II. Rede Metroferroviário RMSP: 2020-2040

III. Conclusão do ferroanel - Tramo Sul e conclusão do ferroanel - Tramo Norte

IV. Integração do aeroporto de Guarulhos com transporte de cargas e passageiros da rede metroferroviária da RMSP

V. Implantação de plataformas logísticas periféricas junto ao ferroanel

VI. Projeto Tietê 3a Etapa (2014-2018)

VII. Projeto Tietê 4a Etapa (2012-2018)

VIII. Programa de corredores de ônibus metropolitanos da EMTU

IX. Hidrovia metropolitana - primeira etapa: trecho Pinheiros-Tietê e hidrovia metropolitana - segunda etapa

X. Implantação de plataformas logísticas urbanas (8 plataformas)

XI. Corredor de ônibus metropolitano Tucuruvi-Guarulhos

XII. Revisão e ampliação do Sistema Viário Metropolitano (Sivim)

XIII. PDMAT 3: Terceiro Plano Diretor de Macrodrenagem da Bacia do Alto Tietê

Fonte: Carteira de Projetos do PAM, Emplasa (2014). Organizado pelos autores. 
Lencioni já alertava para tal movimento desigual no espaço: "A segregação socioespacial se reproduz, com maior ou menor contraste, por todo o território da cidade-região, a expressar, de maneira nítida, a riqueza e a pobreza de uma economia desenvolvida com extrema desigualdade na distribuição da renda" (Lencioni, 2011, p. 146).

Os projetos previstos no PAM para a RMSP estão listados no Quadro 1. Em síntese, é possível notar que, para o horizonte de 2040, estão indicados projetos relativos aos temas (1) infraestrutura de mobilidade, transporte e logística; e (2) coleta e tratamento de esgotos e macrodrenagem, que devem abarcar $67 \%$ do volume total de investimentos previstos para os vetores territoriais da Macrometrópole Paulista. Tal fator é um indicativo bastante relevante de como a ação estatal tende a definir a RMSP como espaço prioritário, mesmo diante de seu projeto de desenvolvimento regional para o território macrometropolitano.

\section{Discussão}

E o que são reterritorialização e reescalonamento para Brenner (2018)? Fundamentalmente, referem-se ao fenômeno da produção do espaço, no qual o capital transnacional em grandes regiões urbanas está estreitamente vinculado a uma nova escala, mais ampla do processo de urbanização em territórios suprarregionais. Diante dessa visão de Brenner, é então possível afirmar, analisando as diretrizes e os conteúdos do PAM como instrumento da ação estatal, que esse enquadramento se expressa na Macrometrópole Paulista? Entendemos que sim, sobretudo quando o autor sublinha que a ação estatal, ao priorizar a "construção de infraestruturas territoriais em larga escala" (ibid., p. 71) e fornecer uma "segunda natureza" de configurações espaciais socialmente produzidas, tais como "ferrovias, rodovias, portos, canais, aeroportos, redes de informação e instituições estatais que permitem a circulação do capital ainda mais rápido", é parte fundamental do processo de reafirmação desses novos territórios e escalas.

Ora, são esses os principais eixos e vetores territoriais de desenvolvimentos previstos no Plano de Ação da Macrometrópole. Os artigos de Tavares (2016) e Asquino (2010) já apontaram que esse caminho de priorização de infraestrutura como estratégia do mercado é o foco da MMP, "que busca orientar regionalizações para provisão de recursos públicos ou privados". Na passagem abaixo do PAM, é possível observar a prioridade desses vetores como estratégia principal para o desenvolvimento da MMP:

Os vetores territoriais são entendidos como conexões que desempenham funções específicas em nível intermetropolitano, incluindo as novas conexões criadas em função de dinâmicas produtivas ou urbanas. Ou, ainda, circuitos que resultam na conformação e/ ou no reforço das novas centralidades. Nesse sentido, os vetores territoriais articulam-se a projetos como os seguintes: (1) a implantação de plataformas logísticas e de recuperação e/ou implantação de rede ferroviária para transporte de carga e de passageiros (Secretaria de Transportes e Logística); (2) os trens regionais e trens metropolitanos (Companhia de Trens Metropolitanos/Secretaria de Transportes Metropolitanos); (3) a estruturação do complexo aeroportuário da MMP (Agência Nacional de Aviação Civil - 
Anac), abrangendo os aeroportos de Guarulhos, Congonhas e Vira-copos, e integrando o transporte aéreo à estrutura de conectividade e transporte da MMP. (PAM, 2014, p. 22)

É justamente na análise da ação estatal na qual se opta pela infraestrutura territorial que Brenner refaz o percurso crítico de Harvey (apud Brenner, 2018, p. 67) para quem "o capital está inerentemente voltado para eliminação das barreiras espaciais ao processo de circulação" e a produção capitalista do espaço se dá pela "construção de infraestruturas de transporte, comunicações e de regulamentação institucional relativamente fixas e imóveis [...] que esse acelerado movimento físico das mercadorias do espaço pode ser obtido" (ibid.).

Verifica-se, na carteira de projetos do PAM, que os vetores territoriais e sistêmicos organizam os projetos estruturantes, que podem estar relacionados tanto à intervenção pública como à iniciativa privada. Os vetores são a base territorial para a implementação dos projetos estruturantes visando ao desenvolvimento econômico da MMP. Tais projetos também foram definidos, pelo governo do estado, para lidar com os principais desafios e gargalos da MMP, sobretudo no que diz respeito à atratividade econômica, à coesão territorial e à urbanização inclusiva. Ademais, os projetos estruturantes foram estabelecidos por vetores territoriais e sistêmicos, para articular as ações que buscam a transversalidade e a integração setorial que o território exige (Emplasa, 2014, p. 23)

No total, o valor de investimentos previstos pela Carteira de Projetos do PAM é da ordem $\mathrm{R} \$ 415$ bilhões. A estimativa é que, anualmente, a implementação dos projetos previstos para MMP envolverá recursos aproximados de $\mathrm{R} \$ 16$ bilhões. Até 2025, os recursos necessários serão da ordem de R\$191 biIhões e, para o período 2025/2035, em torno de $\mathrm{R} \$ 197$ bilhões. Os projetos referentes aos vetores territoriais, que enfatizam o investimento em infraestrutura, têm custo estimado de $R \$ 254$ bilhões, dos quais $R \$ 108$ bilhões, para o primeiro período, e $\mathrm{R} \$ 140$ bilhões, para o segundo, restando $\mathrm{R} \$ 4$ bilhões para o longo prazo (ibid., p. 174).

Os recursos elencados exemplificam, notadamente, a dinâmica e o entendimento prioritário para circulação do capital nesse território, através da ação estatal na escala subnacional, entrelaçada com objetivos mais amplos e transnacionais de produção e circulação. Diante disso, entendemos que ocorre certo acomodamento forjado de configurações socioterritoriais imóveis nas quais a acumulação expandida de capital possa ser gerada; e isso envolve "a conversão das restrições à acumulação, de temporais para espaciais" (Harvey apud Brenner, 2018, p. 67).

Portanto, nesse processo de reterritorialização, quanto mais progressiva for a urbanização de territórios geográficos, mais ocorrerá a articulação de novos espaços policêntricos, redefinindo padrões de centralidade urbana e, ao mesmo tempo, reconstituindo "padrões de polarização centro-periferia através dos quais o capital afirma seu poder sobre o espaço, o território e o lugar" (Keil apud Brenner, 2018, p. 75). E como esses arranjos urbano regionais vêm ocorrendo no caso brasileiro?

Moura (2008) entende que essas novas escalas são estruturas que, no processo de metropolização brasileiro, não se encaixam perfeitamente nos códigos das metrópoles e das aglomerações urbanas. Possuem 
conectividades apoiadas sobre infraestruturas de transporte e comunicações que condicionam seus processos de desenvolvimento e atividades econômicas ao longo dos eixos que interligam suas aglomerações urbanas, intrinsecamente associados à metropolização contemporânea:

Frutos do processo de metropolização contemporâneo - que manifesta espacialmente o modelo de desenvolvimento vigente, mais que morfologias -, configuram-se em polos da diversificação produtiva e da diversidade social, potencializando sua capacidade multiplicadora e aceleradora de fluxos e dinâmicas, e sua condição propícia como localizações privilegiadas à reprodução e à acumulação do capital. (Ibid., p. 39)

De acordo com a autora, a composição dos arranjos urbano-regionais revela concentrações de pobreza e deficiência de serviços à margem da evolução dinâmica - potencialmente favorável - do conjunto das relações socioeconômicas, simultâneo a nichos constituídos por segmentos orientados para a globalização e a reprodução do capital, configurando-se como espaços privilegiados para tal.

Fica claro que o modelo de desenvolvimento mantém seu viés concentrador do crescimento nas grandes aglomerações urbanas, mesmo que se percebam alguns movimentos difusores. Também fica claro que a acumulação segue acentuando as disparidades regionais, articulando e incluindo os territórios funcionais e rentáveis, e excluindo os ineficientes ou pouco competitivos. (Ibid., p. 45)

Dessa maneira, os arranjos urbano-regionais constituem-se em unidades multiescalares que, por um lado, possuem aspectos favoráveis, p.ex., a convergência de interesses para alocação de investimentos públicos ou privados. Mas, por outro, há dificuldades para "[...] o exercício das funções públicas de interesse comum, tão necessário nos espaços aglomerados, dados os distintos interesses das diversas escalas em competição" (ibid., p. 46)

A escala, e sua dinâmica atrelada à produção capitalista no território brasileiro, articulada com a dinâmica global, não é um tema novo. Vainer (2006, p. 11) coloca como crucial a questão da escala da ação política, para a compreensão ou transformação do mundo contemporâneo. Observa-se a necessidade de se superar a visão empirista de relação linear e biunívoca entre um dado fenômeno ao qual corresponde uma escala adequada, em que "a escala de observação (também) define o fenômeno" (Castro, 1997, p. 36 apud ibid.). Hoje, mais que nunca, sobretudo na Macrometrópole Paulista com sua "fronteira frouxa",

a escala deixa de ser porção do espaço, jurisdição - do mercado de trabaIho ou de qualquer outro processo ou fenômeno - para se transformar em campo de fluxos e relações -, relações econômicas, por certo, mas também e, de maneira, inseparável, relações de poder. (Ibid., p. 16)

Assim como Swyngedouw (1997, p. 140 apud Vainer, 2006, p. 18), Vainer acredita que as escalas não estão dadas, nem são fixas, tampouco podem ser reificadas. Rejeitar a reificação das escalas é permitir concebê-las como "a arena e o momento, tanto discursiva quanto materialmente, nos quais relações de poder socioespaciais são contestadas, negociadas e 
reguladas" (Swyngedouw, 1997, p. 140 apud Vainer, 2006, p. 18).

A historicidade dos processos escalares está posta como uma permanente advertência para que evitemos o congelamento confortável das escalas, que, por exemplo, faz termos como "lugar" ou "local" serem noções absolutamente ideológicas, destituídas de qualquer consistência conceitual. Vainer (ibid.) expõe, a partir de uma revisão histórica, que o confortável posicionamento fixo escalar é colocado à prova sob disputas políticas e ideológicas, modificando significados e redefinindo sujeitos e relações:

Assim, é igualmente possível entender que se, de um lado, os confrontos e conflitos ocorrem num mundo escalarmente organizado, de outro, as escalas que organizam o mundo são, elas mesmas, resultantes dos desenlaces de conflitos passados. Para usar a linguagem de Bourdieu, as escalas são estruturadas, mas são também estruturantes. (Ibid., p. 18)

[...] termos como "lugar" ou "local" [são] noções absolutamente ideológicas, destituídas de qualquer consistência conceitual. De que "local" se fala quando se fala de desenvolvimento local: do município brasileiro, da aldeia tailandesa, da comunidade tribal indiana, do county norte-americano, da comuna francesa? (Ibid., p. 27)

Entrar no debate no qual se faz presente o discurso hegemônico da "inevitável" globalização neoliberal exige permanente interpelação de modelos escalares, pois,

Afinal de contas, o poder, mais do que nunca, não está nem no local nem no regional, nem no nacional nem no global... mas na capacidade de articular escalas, de analisar e intervir de modo transescalar. (Ibid., p. 28)

\section{Conclusões preliminares}

A escala de planejamento regional está associada às transformações no âmbito econômico, no qual a globalização e os processos de reescalonamento são fundamentais para se compreender o desenvolvimento desigual. Este artigo discute aspectos conceituais e empíricos dos processos de metropolização do espaço, a partir do estudo da Macrometrópole Paulista, tendo como referência teórica os conceitos de reterritorialização e reescalonamento. Para tanto, caracterizamos o território macrometropolitano, com especial atenção para as estratégias institucionais adotadas pelo Estado subnacional, concluindo que a Macrometrópole Paulista é uma instituição estatal emergente, reescalonada para reterritorialização do capital.

Para Brenner (2018), a consolidação das cidades-globais é um processo que envolve "uma forma histórica específica de aglomeração urbano-industrial que vem ocupando um papel propulsor crucial no mais recente ciclo da globalização" (p. 71). A MMP, ao abranger a recomposição da forma urbana em regiões compactas e policêntricas, assume papel central de organização, via ação estatal, dos núcleos urbanos de acordo com os investimentos em regiões periféricas, mediando a competição de investimentos assim como subsídios de estatais que tendem a elevar ao reforço do desenvolvimento regional desigual.

O processo de desterritorialização, para Brenner, não é apenas uma consequência da 
globalização, mais intrínseco ao seu processo, em seu atual ciclo. Novas configurações espaciais e novas escalas demandam "novas representações de 'escalonamento' de práticas espaciais são necessárias para se compreender a organização territorial em rápida mutação do capitalismo mundial do final do século XX" (ibid., p. 64).

Nesse sentido, no estágio atual da globalização neoliberal, "as cidades e os Estados contemporâneos estão sendo reterritorializados e reescalonados atualmente" (ibid). Sua organização, ou reorganização, é ao mesmo tempo um meio e um resultado "dessa dinâmica de reestruturação espacial global altamente conflitante" (ibid.). Mas como isso tem ocorrido em escalas supranacionais ou subnacionais, quais as especificidades desses processos? Para Brenner, a escala espacial supranacional pode ser observada pela nova configuração da economia mundial dominada pelos blocos super-regionais da Europa, América do Norte e Ásia Ocidental (ibid., pp. 65-66).

Já, nas escalas subnacionais, como a Macrometrópole Paulista, o que se pode perceber é a intensificação da competição "entre as regiões urbanas, que se esforçam para atrair investimentos de capital e subsídios do Estado (ibid., p. 66).

as cidades e os Estados contemporâneos operam não como mutuamente exclusivos ou como configurações geográficas competindo pelo desenvolvimento capitalista, mas como formas de organização territorial interdependentes densamente sobrepostas. Cidades e Estados estão sendo reconfigurados, reterritorializados e reescalonados em conjunto com o mais recente ciclo da globalização capitalista, mas ambos permanecem sendo formas essenciais de organização territorial sobre as quais se baseia a circulação de capital em escala mundial. (Ibid.)

Seria a MMP uma manifestação do argumento de Brenner de "transformação das cidades e dos Estados dentro da dinâmica da reestruturação capitalista global?" (Brenner, ibid.). Em nosso entendimento, sim. Compreendemos a Macrometrópole Paulista como "uma nova instituição estatal emergente reescalonada para reterritorialização do capital" (ibid., p. 80), assim como,

\begin{abstract}
uma estratégia de re-regulamentação para construir novas capacidades institucionais a fim de promover o investimento de capital nos grandes polos de crescimento urbano, geralmente através de políticas de trabalho social local ou regionalmente organizadas, ongs não eleitas e outras iniciativas empresariais, tais como parcerias público-privadas. (p. 81)
\end{abstract}

Tal instituição, com fronteiras políticamente construídas a partir da dependência estatal na formação espacial de seu território e desenvolvimento e reprodução do capital, continua a produzir e reproduzir injustiças e desigualdades regionais no Brasil contemporâneo. 


\section{[I] http://orcid.org/0000-0002-0468-4329}

Universidade de São Paulo, Instituto de Energia e Ambiente, Divisão Científica de Gestão, Ciência e Tecnologia Ambiental. São Paulo, SP/Brasil.

pedrotorres@usp.br

\section{[II] https://orcid.org/0000-0003-2647-6966}

Universidade Federal do ABC, Centro de Engenharia, Modelagem e Ciências Sociais Aplicadas, Programa de Pós-Graduação em Planejamento e Gestão do Território. Santo André, SP/Brasil.

ramosruth78@gmail.com

\section{[III] https://orcid.org/0000-0003-0103-4707}

Universidade Federal do ABC, Centro de Engenharia, Modelagem e Ciências Sociais Aplicadas, Programa de Pós-Graduação em Planejamento e Gestão do Território. Santo André, SP/Brasil. apollachi@gmail.com

\section{Notas}

(*) Os autores agradecem a leitura e a contribuição dos professores doutor Pedro Roberto Jacobi (USP) e doutor Klaus Frey (UFABC). O presente artigo é fruto de pesquisa realizada no âmbito do Projeto Temático Fapesp 2015/03804-9, processo 2019/05644-0 e 2018/06685-9.

(1) Decreto estadual n. 52.742 de 26/2/2008 que criou Grupo de Trabalho para propor alternativas de aproveitamento dos recursos hídricos da Macrometrópole de São Paulo. Artigo 1ㅇ) Fica instituído Grupo de Trabalho encarregado de revisar os estudos existentes e propor um conjunto de alternativas de novos mananciais para o uso múltiplo de recursos hídricos da Macrometrópole de São Paulo, visando a contribuir para o seu desenvolvimento sustentável, com prioridade para o abastecimento público, bem como diretrizes para o aproveitamento dos mananciais existentes e medidas de racionalização do uso da água até o horizonte de 30 (trinta) anos, considerada a viabilidade técnica, econômico-financeira, institucional e ambiental de cada uma delas.

(2) A publicação "Estudo da Morfologia e da Hierarquia Funcional da Rede Urbana Paulista e da Regionalização do Estado de São Paulo" traz a informação que, em um documento interno mimeografo de 2006, a Emplasa definiu a configuração da MMP.

(3) “O recorte territorial da MMP do PDARH-MMP é anterior à MMP do PAM, é um pouco diferente e maior do que a MMP, abrangendo 180 municípios, oito a mais que o PAM. Trata-se de ação da maior relevância e pioneira no planejamento e gestão de recursos hídricos de forma integrada e intersetorial (Emplasa, p. 77, carteira de projetos).

(4) Nesse sentido, é importante ressaltar que os trabalhos de Sandra Lencioni sobre "novo fato urbano" são frequentemente mencionados nas publicações sobre a MMP da Emplasa (Lencioni, 2005).

(5) Os artigos de Tavares (2018) e Júnior e Castro (2017) trazem informações mais detalhadas.

(6) Lei $n$. 14.676 de 28/12/2011. 
(7) São considerados vetores de desenvolvimento no PAM: 1) Vetor de Desenvolvimento Região Metropolitana de São Paulo - abrange o território da RMSP; 2) Vetor de Desenvolvimento Bandeirantes - abrange a ligação de São Paulo/Jundiaí/Campinas/Rio Claro/Piracicaba; 3) Vetor de Desenvolvimento Vale do Paraíba - abrange a ligação São Paulo/São José dos Campos/ Taubaté; 4) Vetor de Desenvolvimento Caminho do Mar - abrange as ligações entre os centros logísticos, as vias e os modos de transposição da Serra do Mar, para carga e passageiros, em direção aos acessos do porto de Santos; 5) Vetor de Desenvolvimento Sorocaba - abrange a região a oeste da MMP, no eixo das rodovias Castelo Branco e Raposo Tavares; 6) Vetor de Desenvolvimento Perimetral da Macrometrópole - abrange faixa territorial formada a partir do porto de São Sebastião/São José dos Campos/Jacareí/Campinas e Sorocaba.

(8) O termo "fronteira frouxa" é utilizado por Zioni et al. (2019), para reforçar as dificuldades de se operar com uma territorialidade definida de "cima para baixo", não levando em consideração, por exemplo, as Unidades de Gerenciamento dos Recursos Hídricos, que determinam uma "outra Macrometrópole Paulista", com contornos distintos da cartografia-base da Emplasa.

\section{Referências}

ASQUINO, A. (2010). A importância da Macrometrópole Paulista como escala de planejamento de infraestruturas de circulação e de transporte. Revista Brasileira de Estudos Urbanos e Regionais, v. 12 , n. 1 , pp. 83-98.

AZEVEDO, S.; SANTOS JUNIOR, O. A. dos e RIBEIRO, L. C. Q. (2009). Mudanças e permanências na cultura política das metrópoles brasileiras. Dados. Rio de Janeiro , v. 52, n. 3, pp. 691-733.

BRANDÃO, C. A.; FERNÁNDEZ, V. R. e RIBEIRO, L. C. de Q. (2018). Escalas espaciais, reescalonamentos e estatalidades: lições e desafios para América Latina. Rio de Janeiro, Observatório das Metrópoles/ Letra Capital.

BRENNER, N. e THEODORE, N. (2005). Neoliberalism and the urban condition. City, v. 9, n. 1, pp. 101-107. doi:10.1080/13604810500092106.

BRENNER, N. (2010). A globalização como reterritorialização: o reescalonamento da governança urbana na União Europeia. Cadernos Metrópole. São Paulo, v. 12, n. 24, pp. 535-564.

(2018). Espaços da urbanização. O urbano a partir da teoria crítica. Rio de Janeiro, Letra Capital.

CAMPOLINA DINIZ, C. e CAMPOLINA, B. (2007). A região metropolitana de São Paulo: reestruturacao, re-espacializaçao e novas funções. Eure. Santiago, v. 33, n. 98, pp. 27-43.

CHELOTTI, M. C. (2010). Reterritorialização e Identidade Territorial. Sociedade \& Natureza. Uberlândia, v. 22 , n. 1 , pp. $165-180$.

CUNHA, J. M. P. et al. (2013). A mobilidade pendular na Macrometrópole Paulista: diferenciação e complementaridade socioespacial. Cadernos Metrópole. São Paulo, v. 15, n. 30, pp. 433-459. 
DAEE - Departamento de Água e Energia (2013). Secretaria de Saneamento e Recursos Hídricos. Plano Diretor de Aproveitamento dos Recursos Hídricos para Macrometrópole Paulista. São Paulo.

EMPLASA - Empresa Paulista de Planejamento Metropolitano S.A. (2011a). Estudo da morfologia e da hierarquia funcional da rede urbana paulista e regionalização do Estado de São Paulo. Extrato. Documento 2. Resultados.

(2011b). Rede urbana e regionalização do Estado de São Paulo. São Paulo.

(2014). Plano de Ação da Macrometrópole Paulista. Volume 2: Uma visão da Macrometrópole 2013-2040. São Paulo.

(2014). Plano de Ação da Macrometrópole Paulista. Volume 4: Carteira de Projetos do PAM. São Paulo.

(2019). Disponível em: https://emplasa.sp.gov.br/MMP. Acesso em: maio de 2019.

FREY, K. (2019). Global city-region. The Wiley Blackwell Encyclopedia of Urban and Regional Studies. Edited by Anthony Orum. JohnWiley \& Sons.

GOMES, T. Von Z. (2018). Macrometrópole Paulista: formação de uma agenda seletiva de venda de uma região - caso dos projetos de transporte. Dissertação de Mestrado. Santo André, Universidade Federal do $A B C$.

HAESBAERT, R. (2006). “Concepções de território para entender a desterritorialização”. In: SANTOS, M. et al. Território, territórios: ensaios sobre ordenamento territorial. Rio de Janeiro, DP\&A.

IBGE (2010). Censo Demográfico 2010. Características da população e dos domicílios: resultados do universo. Rio de Janeiro, IBGE.

(2015). Estimativas da população residente nos municípios brasileiros com data de referência em 1ㅇ de julho de 2015: [notas metodológicas]. Rio de Janeiro, IBGE, Coordenação de População e Indicadores Sociais.

JACOBI, P. R.; CIBIM, J.; LEÃO, R. de S. (2015). Crise hídrica na Macrometrópole Paulista e respostas da sociedade civil. Estudos Avançados. São Paulo, v. 29, n. 84, pp. 27-42.

JÚNIOR, W. R. S. e CASTRO, H. R. (2017). A expansão da Macrometrópole e a criação de novas RMs: um novo rumo para a metropolização institucional no estado de São Paulo? Cadernos Metrópole. São Paulo, v. 19, n. 40, pp. 703-720.

KLINK, J. (2013). Development regimes, scales and state spatial restructuring: change and continuity in the production of urban space in Metropolitan Rio de Janeiro, Brazil. International Journal of Urban and Regional Research, v. 37, n. 4, pp. 1168-1187.

KLINK, J., OLIVEIRA, V. e ZIMERMAN, A. (2013). Neither spatial Keynesianism, nor competitive neolocalism: rescaling and restructuring the developmental state and the production of space in Brazil. International Journal of Urban Sustainable Development, v. 5, n. 1, pp. 25-39.

LENCIONI, S. (2005). A emergência de um novo fato urbano de caráter metropolitano em São Paulo. Boletim Paulista de Geografia, v. 82, pp. 45-64.

(2011). A metamorfose de São Paulo: o anúncio de um novo mundo de aglomerações difusas. Revista Paranaense de Desenvolvimento. Curitiba, n. 120, pp. 133-148.

(2015a). Urbanização difusa e a constituição de megarregiões. O caso de São Paulo-Rio de Janeiro. E-metropolis, n. 22. 
LENCIONI, S. (2015b). Região Metropolitana de São Paulo como centro da inovação do Brasil. Cadernos Metrópole. São Paulo, v. 17, n. 34, pp. 317-32.

MOURA, R. (2008). Arranjos urbano-regionais: uma categoria complexa na metropolização brasileira. Revista Brasileira de Estudos Urbanos e Regionais, [S.I.], v. 10, n. 2, pp. 29-49.

MOURA, R. e PÊGO, B. (2017). O sistema urbano brasileiro e suas articulações na escala sul-americana. Boletim regional, urbano e ambiental. Ipea. Brasília, n. 16, pp. 71-81.

NEGREIROS, R.; SANTOS, S. M. M. e MIRANDA, Z. A. I. (2015). Nova escala de planejamento, investimento e governança na Macrometrópole Paulista. Revista Iberoamericana de urbanismo, n. 12, ano 7, pp. 121-136.

NUNES COELHO MAGALHÃES, F. (2008). Da metrópole à cidade-região. na direção de um novo arranjo espacial metropolitano? Revista Brasileira de Estudos Urbanos e Regionais, v. 10, n. 2, pp. 9-27.

OLIVEIRA, F. (1995). “Neoliberalismo à brasileira”. In: SADER, E. e GENTILI, P. (orgs.). Pós-neoliberalismo: as políticas sociais e o Estado democrático. Rio de Janeiro, Paz e Terra.

PASTERNAK, S. e BÓGUS, L. M. M. (2019). Macrometrópole paulista: estrutura sócio-ocupacional e tipologia dos municípios - Mudanças na primeira década dos anos 2000. Revista Brasileira de Estudos Urbanos e Regionais, v. 21, n. 2, pp. 431-450.

RIBEIRO, L. C. Q.; SANTOS JÚNIOR, O. A. e AZEVEDO, S. (2009). Mudanças e permanências na cultura política das metrópoles brasileiras. Dados. Rio de Janeiro, v. 52, pp. 691-733.

SÃO PAULO (2008). Governo Estadual. Decreto estadual n. 52.742, promulgado em 26 de fevereiro de 2008.

SASSEN, S. (1991). The Global City: New York, London, Tokyo. Princeton,Princeton University Press. (1993). Cities in the World Economy. Londres, Sage.

SCOTT, A. J. (ed.) (2001). Global city-regions: trends, theory, policy. Nova York, Oxford University Press.

SILVA, K. A. A; CUNHA, J. M. P. e ORTEGA, G. M. (2017). Um olhar demográfico sobre a constituição da macrometrópole paulista: fluxos populacionais, integração e complementariedade. Cadernos Metrópole. São Paulo, v. 19, n. 40, pp. 721-748.

SOJA, E. W. (2000). Postmetropolis: critical studies of cities and regions. Malden US and Oxford UK, Blackwell Publishers.

SOUZA, M. (2016). Reescalonamento espacial do estado desenvolvimentista no Brasil /The spatial rescaling of the developmental state in Brazil. Mercator, v. 15, n. 4, pp. 27-46.

STORPER, M. (1996). The regional world: territorial development in a global economy. Nova York, Guilford.

TAVARES, J. C. (2016). Eixos: novo paradigma do planejamento regional? Os eixos de infraestrutura nos PPA's nacionais, na lirsa e na Macrometrópole paulista. Cadernos Metrópole. São Pauo, v. 18, n. 37, pp. 671-695.

TAVARES, J. (2018). Formação da macrometrópole no Brasil: construção teórica e conceitual de uma região de planejamento. Eure, v. 44, n. 133, pp. 115-134. 
TORRES, P. H. C; RAMOS, R. F. e GONÇALVES, L. R. (2019). Conflitos ambientais na macrometrópole paulista: Paranapiacaba e São Sebastião. Ambiente \& Sociedade. São Paulo, v. 22.

VAINER, C. B. (2006). Lugar, região, nação, mundo: explorações históricas do debate acerca das escalas da ação política. Revista Brasileira de Estudos Urbanos e Regionais, v. 8, n. 2, pp. 9-29.

ZIONI, S., TRAVASSOS, L.; MOMM, S. e LEONEL, A. L. (2019). “A Macrometrópole Paulista e os desafios para o planejamento e gestão territorial”. In: TORRES, P.; JACOBI, P. R.; BARBI, F. e GONÇALVES, L. R. (orgs.). Governança e planejamento ambiental: adaptação e políticas públicas na macrometrópole paulista. Rio de Janeiro, Letra Capital.

Texto recebido em 17/jun/2019

Texto aprovado em 29/ago/2019 